\title{
Improving the quality of cutting flat glass
}

\author{
Martin Svoboda ${ }^{1, *}$, Josef Soukup ${ }^{1}$, Milan Sapieta ${ }^{2}$ \\ ${ }^{1}$ Faculty of Pruduction Technology and Management Jan Evangelista Purkyně University in Ústí nad \\ Labem, Department of Machines and Mechanics, 400 96, Pausterova 1, Ústí n/L, Czech Republic \\ ${ }^{2}$ Faculty of Mechanical Engineering, Univerzity of Zilina. Univerzitna 1, 01026 Zilina. Slovak \\ Republic
}

\begin{abstract}
The article deals with improving the quality of the cut flat glass. The aim of the study was to determine mechanism of origin temporary and permanent stress in the glass. This affects the quality of the cut flat glass. Of the commonly measured process parameters were adjusted following an evaluation, better cooling of flat glass between the furnace and the point of cutting into a prescribed format glass. The results are applicable for flat glass production lines.
\end{abstract}

Keywords: flat glass, float system, measurement, stress

\section{Introduction}

The research deals with the problem of cutting quality of flat glass. There is described a draft general procedure for obtaining the best adjustment of the cooling equipment for a given thickness, width and shade of the glass, which is manufactured on a production line of flat glass - float system.

The most of the world's production of float glass produced by the process of "float" (float glass). Other methods of production (drawing, rolling) either gradually or completely disappear or are intended for smaller production of specialty flat glass.

The typical properties of glass are that during cooling from high temperatures crystallises after reaching the liquidus temperature immediately throughout its mass. Another cooling it still retains the character of the liquid. For this reason this material is called a super cooled liquid $[1-3,8,9]$.

\section{Production of flat glass by float system}

Float process is a special way of forming the glass where the glass stream entering the chamber with the molten tin. On the tin was uniformly flowing and obtains a uniform thickness and a smooth surface (Fig. 1). At present all flat glass production methods are also used for the manufacture of insulating glass. They are formed from two or more pieces of glass with an air cavity or a cavity filled with an inert gas (ie. insulating glazing or triple glass).

\footnotetext{
*Corresponding author: svoboda@fvtm.ujep.cz

Reviewers: Andrej Czán, Juraj Gerlici
} 
Modern companies producing the flat glass on one line only. The problem with this production is a lingering residual stress. Enduring value temporary stress has a negative impact on the quality of the cut and the refractive of the glass.

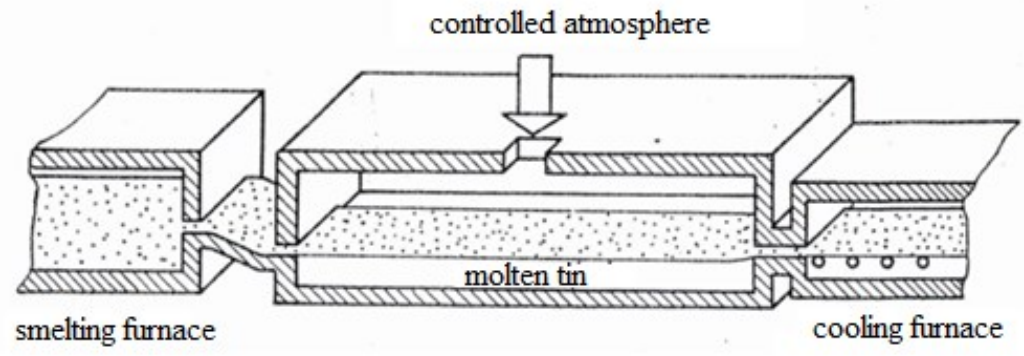

Fig. 1. The principle of manufacturing flat glass by the float system [4]

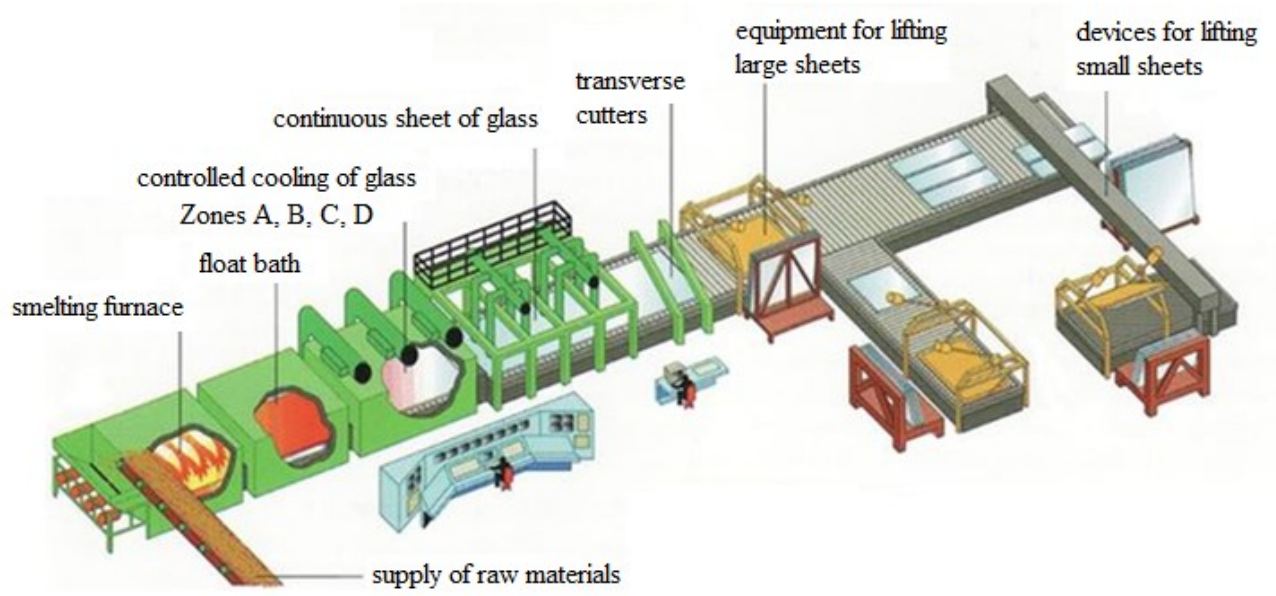

Fig. 2. Scheme flat glass production line [5]

Figure 2 illustrates the production of flat glass "float system". The cooling chamber has four cooling zone A, B, C, D in a direction of flow. In these zones is adjusted gradually cooling the glass sheets by means of air nozzles.

With the first phase of cutting glass (making an incision in the glass) is also linked to the creation a large field of residual stresses in the material being cut. These stresses in the material can be easily observed in polarized light. Residual stress is a result of plastic deformation caused by the cutting tool. The brittle material is important because residual stress to produce uniform and crack propagation at the contact point of the cutting tool and the material to be cut. Field of residual stress also significantly affects the growth of cracks due to follow the voltage is applied during the actual breaking glass [4-6].

For a good a quarry of glass has a decisive influence its structure. This depends on its composition and on the method of manufacture. Glass body deforms elastically until the moment when comes to an abrupt a quarry of glass [7-9]. The quarry is brittle with no apparent plastic deformation. Strength of glass is largely influenced by the quality of the surface (surface defects), the type of specimen and loading conditions. 


\section{Measurement of parameters flat glass production}

By the measurements we have found that the tension is constant in the passage of the glass under unchanging production conditions. It has also been shown that changes in temperature during the day do not greatly affect the magnitude of stress and that the unbalanced setting of cooling across the glass pane greatly influences the shape of the stress curve.

Measurement of the stability of the stress in the glass was a preparatory work and is carried out to check the stress and temperature stability under the constant other conditions of production (especially the setting of the cooling device). The waist stress was measured continuously in front of the longitudinal notch device. The measured values were displayed on the display and saved in *.xls format.

From the measured values the temperature and stress dependence in the glass was processed depending on the width of the glass passage (Fig. 3). The camera begins to measure the passport of the glass at a point where a beam of polarized light strikes the edge of the glass, then the next value of the temperature and magnitude of the transient stress is always measured after $10 \mathrm{~cm}$.

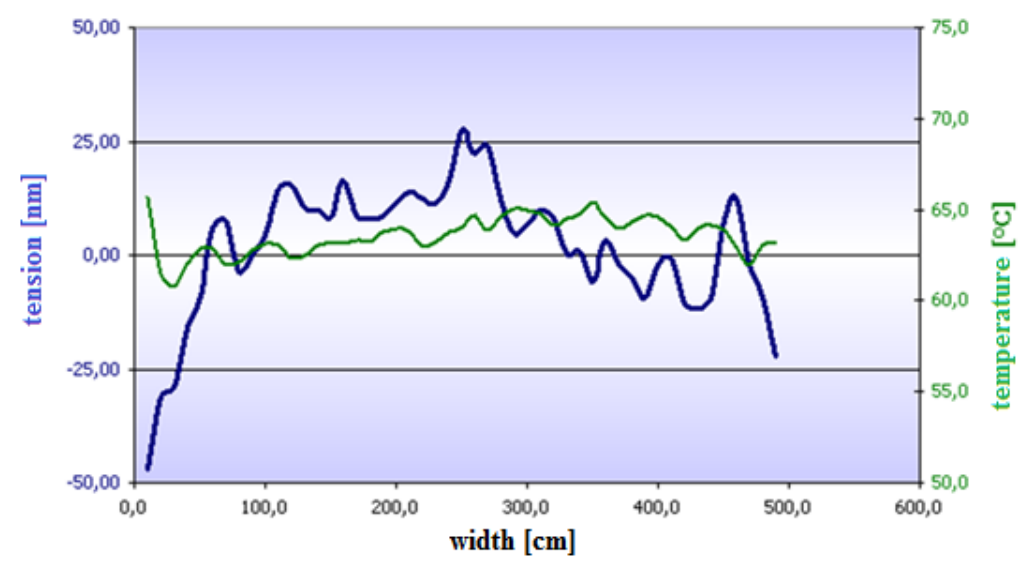

Fig. 3. Tension in the glass waist - glass thickness $4 \mathrm{~mm}$

The flat glass was measured five times immediately in succession (for verify the stability of the stresses). For all measured values, the average value (both internal and internal stress) and the standard deviation were determined in each waist width of the glass. When measuring the temperature across the waist of the sheet glass, the standard deviation of the measurement $\pm 0.38^{\circ} \mathrm{C}$ was determined. For stresses, the standard deviation was $\pm 2.01 \mathrm{~nm} / \mathrm{cm}$.

The change of the pressure and temperature of the glass waist was also evaluated, depending on the change in the temperature in the production hall (again under the constant other physical and production conditions). The sheet of glass moves from the end of the cooling device to the breaking point for 2 to 5 minutes (according to the width of the glass waist). Fluctuations in air temperature in the refrigerating device, which would significantly affect the stresses in the passage of the glass, have also not been demonstrated. It can be stated that the temperature and stress behavior of the glass during the day did not correspond to changes in the day's room temperature. Air humidity was not measured.

It was important to determine the stress values depending on the width of the waist (Fig. 4). This dependence results in considerable unevenness in the width of the stresses 
across the width (Fig. 5.). This is caused by the uneven cooling of the glass over the waist width due to the setting of the cooling nozzles.

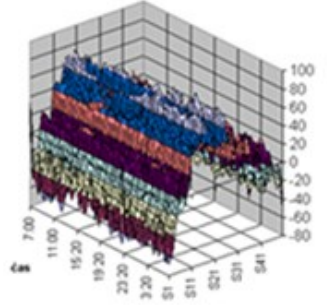

a) the stresses in the glass (24 hours/3D

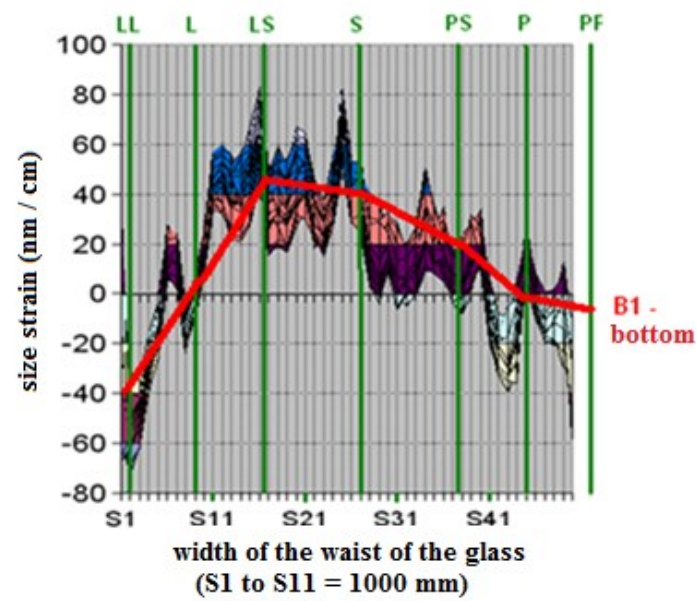

b) the strain on the width of the waist of the glass

Fig. 4. Dependence of tension at the waist of the glass over 24 hours

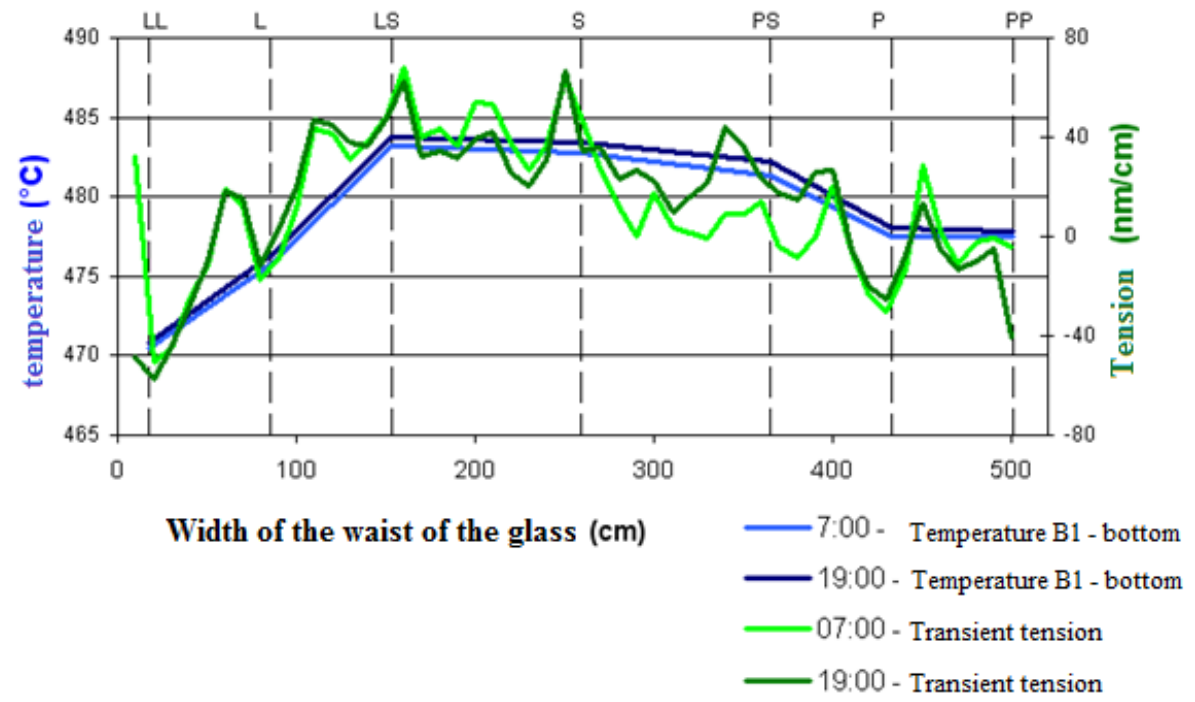

Fig. 5. Tension and temperature of the waist glass zone B - Bottom of the glass

\section{Solutions and discussions}

In the cooling zones $\mathrm{A}, \mathrm{B}, \mathrm{C}$ and $\mathrm{D}$ of the production line, seven temperature sensors are located for the cooling temperature control. Their deployment across the waist of the glass can be seen in Tab. 1. 
Until now, when changing the thickness of the glass passport, the temperatures in the cooling device have been set according to the settings previously made. When adjusting the cooling device, the last acceptable setting was always found, but not the optimal or at least the setting that exhibited the best stresses or the smallest percentage of glass cut glass produced.

Table 1. Location of glass temperature sensors

\begin{tabular}{|l|l|l|l|l|l|l|l|}
\hline Sensor designation & L & ML & CL & C & CR & MR & R \\
\hline Distance from waist center [cm] & 242 & 174 & 106 & 0 & 106 & 174 & 242 \\
\hline
\end{tabular}

Choosing the most suitable chiller setting from a given dataset was done only for a width of $475 \mathrm{~cm}$ (the most common waist width). For this breadth, over a one-and-a-half year period, most of the days when stress measurements were made (both during production and residual) and quality control were also carried out (Tab. 2).

On the basis of the measurements, the best specified cooling parameters have been set. The choice was made mainly according to the shape of the stress curves, which is measured continuously during production (behind the cooling device). The reason for the selection was that individual cut flat glass formats were cut and subsequently fractured with the still persisting transient stress in the glass. The choice was made by gradually eliminating individual settings of the furnace, which were considered the worst of the gradually decreasing amount of stress curves.

Table 2. Faulty boards due to a bad cut

\begin{tabular}{|c|c|c|c|c|c|c|c|c|}
\hline \multirow[b]{2}{*}{ Date } & \multirow{2}{*}{$\begin{array}{l}\text { Glass } \\
\text { width } \\
\text { (cm) }\end{array}$} & \multirow{2}{*}{$\begin{array}{c}\text { Number } \\
\text { of }\end{array}$} & \multicolumn{4}{|c|}{ Type of defect } & \multirow{2}{*}{$\begin{array}{l}\text { Number } \\
\text { of } \\
\text { defective } \\
\text { products }\end{array}$} & \multirow{2}{*}{$\begin{array}{c}\text { Faulty } \\
\text { products } \\
{[\%]}\end{array}$} \\
\hline & & & $\begin{array}{l}\text { glued } \\
\text { shard }\end{array}$ & Mussels & $\begin{array}{l}\text { Bad } \\
\text { quarry }\end{array}$ & $\begin{array}{l}\text { Other } \\
\text { defect }\end{array}$ & & \\
\hline 27.10 .2008 & 475 & 56 & 0 & 1 & 0 & 0 & 1 & 1.79 \\
\hline 29.10 .2008 & 475 & 88 & 1 & 4 & 0 & 1 & 6 & 6.82 \\
\hline 30.10 .2008 & 475 & 78 & 0 & 3 & 0 & 0 & 3 & 3.85 \\
\hline 26.11 .2008 & 475 & 86 & 0 & 2 & 0 & 0 & 2 & 2.33 \\
\hline 27.11 .2008 & 475 & 125 & 0 & 2 & 0 & 0 & 2 & 1.60 \\
\hline 29.11 .2008 & 475 & 60 & 0 & 0 & 1 & 0 & 1 & 1.67 \\
\hline 30.11 .2008 & 475 & 60 & 0 & 0 & 0 & 0 & 0 & 0.00 \\
\hline 1.12 .2008 & 475 & 102 & 1 & 1 & 0 & 0 & 2 & 1.96 \\
\hline 2.12 .2008 & 475 & 110 & 0 & 2 & 0 & 0 & 2 & 1.82 \\
\hline
\end{tabular}

Figure 6 shows the residual stress curve of the day when no defective fractures were found during the production of the glass waist to the predetermined sheet formats. The right part of the chart shows lower stresses in the glass pane (highlighted with red lines).

Proposal for setting a cooling device for the thickness of $3.15 \mathrm{~mm}$, width of $475 \mathrm{~cm}$ in the Tab. 3. It was obtained by mirroring the right half that had a lower stress around the central heat sensor.

On the basis of the measurements made, it can be stated that the stresses are constant during constant production conditions in the waist of the flat glass.

Looking at the transverse distribution of stresses in the waist of the glass, it was important to find out that the cross section of the glass has a disproportionate temperature distribution 
at the bottom of the cooling device. The shape of the transient stress curve showed reflection in the heat exchanger settings under the glass pane in zones $\mathrm{A}$ and $\mathrm{B}$.

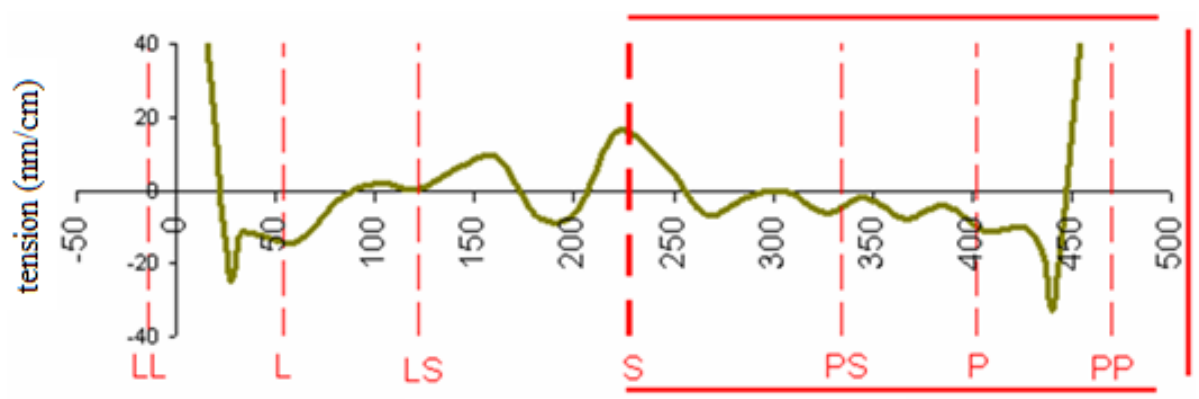

Distance from the left edge $(\mathrm{cm})$

Fig. 6. Tension course during the day ( $24 \mathrm{hrs})$ - average depending on the width of the passport of 30 January 2008

Table 3. Design for setting the cooling in the cooling device (Glass thickness $3,15 \mathrm{~mm}$, width $475 \mathrm{~cm}$ glass)

\begin{tabular}{|c|c|c|c|c|c|c|c|}
\hline \multicolumn{8}{|c|}{ Top of the waist of the glass } \\
\hline $\begin{array}{c}\text { Cooling } \\
\text { zones }\end{array}$ & $\mathbf{L L}$ & $\mathbf{L}$ & $\mathbf{L S}$ & $\mathbf{S}$ & PS & $\mathbf{P}$ & $\mathbf{P P}$ \\
\hline A & 514 & 528 & 528 & 529 & 528 & 528 & 514 \\
\hline B & 443 & 455 & 456 & 457 & 456 & 455 & 443 \\
\hline $\mathbf{C}$ & 390 & 393 & 390 & 385 & 390 & 393 & 390 \\
\hline D & 263 & 280 & 275 & 270 & 275 & 280 & 263 \\
\hline \multicolumn{8}{|c|}{ Bottom of the waist of the glass } \\
\hline & $\mathbf{L L}$ & $\mathbf{L}$ & LS & $\mathbf{S}$ & PS & $\mathbf{P}$ & $\mathbf{P P}$ \\
\hline $\mathbf{A}$ & 505 & 534 & 539 & 539 & 539 & 534 & 505 \\
\hline B & 449 & 470 & 475 & 473 & 475 & 470 & 449 \\
\hline $\mathbf{C}$ & 388 & 419 & 426 & 423 & 426 & 419 & 388 \\
\hline D & 290 & 329 & 342 & 332 & 342 & 329 & 290 \\
\hline
\end{tabular}

It has been demonstrated that the same temperature setting in the individual zones of the refrigeration device (even at a few weeks apart) has shown a constant value.

For the most suitable setting of the cooling device, it should be set for each thickness, width and color of glass produced, and include the metrological conditions.

- The following recommendations were made from the above measurements and analyzes:

- create an internal database for individual shades, thickness and width of the flat glass. This database will store data on the amount of tension created (measured on-line camera before the cut and measured residual stress on the chilled glass sheet), setting the glass waist cooling and the quantity of defective products. It will also keep records of temperature and humidity in the production hall and the outdoor environment. For this reason, it would be necessary to purchase a meteorological station (for outdoor measurements) that will allow connection to the intranet. Perform installation of temperature, pressure and humidity sensors into the air intake into the cooling furnace 
- the creation of a database (history) of the values measured by the meteorological station and the air intake to the cooling furnace together with the values set in the cooling for each thickness, shade and width of the waist of the glass. This will allow quick adjustment of the cooling values.

- Refine cooling, set the bottom (and top) part of the cooling device to the desired temperature at the given point of the glass pane. This applies mainly to zones A and B. Consider the use of autoregulation at the bottom of the cooling furnace.

\section{Conclusions}

The paper describes the problems encountered in the production of sheet glass by the "float" process. Data collection options have been reported, which are normally measured and stored on the production line. Based on the evaluation of the measured data, a procedure was developed for setting the cooling part of the line for individual thicknesses, shades and width of the waist of the glass. Additionally, recommendations were made to create a value database for quick cooling settings to provide lower stresses in the glass, depending on the thickness, width and color of the glass. This recommendation includes expanding the collection of meteorological data in the hall and intake of air to the cooling device, creation of a cooling furnace database including all measured parameters and the possibilities of working with them.

This article was supported by Student Grant Competition of J. E. Purkyně University in Ústí nad Labem.

\section{References}

1. J. Dluhoš, Materiály a technologie - plasty a vybrané nekovové materiály. (Ostrava, Ostravská Univerzita, ISBN 80-7042-052-9, 1993)

2. A. Smrček, F. Oldřich, Sklářské suroviny. (Praha, Informatorium, ISBN 80-85427-478, 1994)

3. F. Schill, Chlazení skla. (Praha, Informatorium, ISBN 80-85427-34-6, 1993)

4. J. Belda, Sklářské a keramické stroje. (Liberec, Fakulta strojní, ISBN 80-7083-149-9, 1994)

5. http://www.autoskloczech.cz/autoskla.htm [cit. 2.11.2008]

6. L. Dušek, P. Němec, D. Veselý, Teorie řezu skla - výzkumná zpráva. (Pardubice, Univerzita Pardubice, Fakulta chemicko-technologická, 2003)

7. J. Menčík, Pevnost a lom skla a keramiky. (Praha, SNTL - Nakladatelství technické literatury, ISBN 80-03-00205-2, 1990)

8. J. Dižo, M. Blatnický, B. Skočilasová, Computational modelling of the rail vehicle multibody system including flexible bodies. Communications: scientific letters of the University of Zilina, 17 (3), 31-36, ISSN 1335-4205, (2015)

9. M. Sapieta, V. Dekys, O. Stevka, Localization Lüders band in infrared spectrum. Applied mechanics and materials 420, 194-201 (2013) 